\title{
Effects of continuous positive airway pressure on respiratory mechanics and breathing pattern in healthy individuals
}

\author{
E Soilemezi ${ }^{*}$ E Koco, M Oikonomou, M Georgiadis, D Matamis \\ From ESICM LIVES 2015 \\ Berlin, Germany. 3-7 October 2015
}

\begin{abstract}
Introduction
Variable levels of positive end expiratory pressure (PEEP) are widely used during mechanical ventilation or during spontaneous breathing for acute or chronic lung diseases. In this study, respiratory indirect plethysmography (RIP), electromyography (EMG) of the transversus abdominis and scalene muscles and indirect calorimetry are used to achieve an integrated picture of the changes in the respiratory system after exposure to $10 \mathrm{cmH}_{2} \mathrm{O}$ CPAP.
\end{abstract}

\section{Objectives}

To investigate the changes in breathing pattern, respiratory muscle mechanics and work of breathing induced by $10 \mathrm{cmH}_{2} \mathrm{O}$ of continuous positive airway pressure (CPAP).

\section{Methods}

Fourteen young, healthy individuals participated in the study, assessed in the semi-recumbent position initially at ZEEP and then at $10 \mathrm{cmH}_{2} \mathrm{O}$ CPAP. RIP was used to evaluate the contribution of the rib cage (RC) and abdominal (AB) compartments to the inspired tidal volume, and to allow measurement of the continuous degree of asynchrony between the thoracic and abdominal movements. EMG activity of the accessory respiratory muscles (transversus abdominis and scalene muscles) and measurements of oxygen consumption (V02) were recorded during both ZEEP and CPAP settings.

\section{Results}

Tidal volume increased from ZEEP $(738 \pm 208 \mathrm{ml})$ to CPAP $(896 \pm 272 \mathrm{ml}, \mathrm{p}<0,05)$ with RIP revealing that this increase was mainly due to $\mathrm{RC}$ rather than $\mathrm{AB}$ contribution. No significant thoraco-abdominal asynchrony was

Papageorgiou General Hospital, Thessaloniki, Greece observed in the CPAP setting. During the first twenty breaths during CPAP the difference between mean tidal volume inspired $(862 \pm 235 \mathrm{ml})$ and mean tidal volume expired $(831 \pm 875 \mathrm{ml})$ was $31 \mathrm{ml}$, and the volume trapped was approximately $600 \mathrm{ml}$. This volume trapped was accommodated during the first four CPAP breaths, after which mean tidal volume inspired and mean tidal volume expired did not differ significantly. EMG recordings indicated increased inspiratory activity of the scalene muscles and increased expiratory activity of the transversus abdominis during CPAP, leading to an increase in oxygen consumption from $278 \pm 40 \mathrm{ml} / \mathrm{min}$ to $322 \pm 52 \mathrm{ml} / \mathrm{min}$ $(\mathrm{p}<0,05)$ measured with indirect calorimetry.

\section{Conclusions}

In normal individuals $10 \mathrm{~cm} \mathrm{H}_{2} \mathrm{O}$ of CPAP induces acute overdistention. This overdistension activates the accessory respiratory muscles and increases the work of breathing. The increased inspiratory scalene muscle activity during CPAP explains the increased RC contribution to tidal volume, whereas the expiratory transversus abdominis recruitment probably defends the lung from overinflation by pulling back the diaphragm towards the initial FRC position. We can assume that in patients with acute respiratory failure not tolerating various levels of CPAP, CPAP induces over-distension and increases the work of breathing.

Published: 1 October 2015

doi:10.1186/2197-425X-3-S1-A268

Cite this article as: Soilemezi et al:: Effects of continuous positive airway pressure on respiratory mechanics and breathing pattern in healthy individuals. Intensive Care Medicine Experimental 2015 3(Suppl 1):A268.

\section{SpringerOpen ${ }^{\circ}$}

(C) 2015 Soilemezi et al.; This is an Open Access article distributed under the terms of the Creative Commons Attribution License (http:// creativecommons.org/licenses/by/4.0), which permits unrestricted use, distribution, and reproduction in any medium, provided the original work is properly cited. 